\title{
ARTICLES
}

\section{KNOWLEDGE AND PRACTICE ON IV CANNULATION AMONG NURSES}

\author{
Sr. Thresiamma NC. (Sr. Litty SH)*| Dr. S. Rajina Rani **
}

${ }^{*}$ Research Scholar, Himalayan University, Itanagar in Arunachal Pradesh, India. \& Lecturer, St. John's College of Nursing, Idukki, Kerala, India.

** Research Supervisor, Himalayan University, Itanagar in Arunachal Pradesh, India. DOI: http://doi.org/10.47211/idcij.2021.v08i01.008

\section{ABSTRACT}

Background: PIVC (Peripherally Intravenous Cannulation) is common invasive procedure in all hospital settings and nurses had a vital role in performing PIVC. It is the only fastest way to deliver any medications to the body. For fruitful insertion of cannulation the trainers should have proper knowledge and practical skills to succeed this procedure with minimum complication and positive client outcome with treatment. The objective was to determine the level of knowledge and practice on IV cannulation and its association with selected demographic and clinical variables. Materials and methods: By using convenience sampling technique 54 participants were recruited based on inclusion criteria. The study was conducted in St. John's Hospital, Idukki. After gaining informed consent, data was collected by using self-structured questionnaire consisting demographic and clinical characteristics, questions regarding knowledge on IV cannulation and observational checklist for identifying practical skills in IV procedure. Results: Data was statistically analysed using SPSS version 20. Samples of 33(68.8\%) had average and $10(20.8 \%)$ had poor knowledge on IVC. Regarding practical performance, 27(56.3\%) had average, 16 (33.3\%) had good skills in IVC. Whereas 5(10.4\%) had very poor practical skills on IVC. This study concluded that knowledge and practical skills in IVC should be improved by attending induction classes which can promote standardised care.

Key words: Intravenous cannulation, knowledge, practice, staff nurses.

\section{ABOUT AUTHORS:}

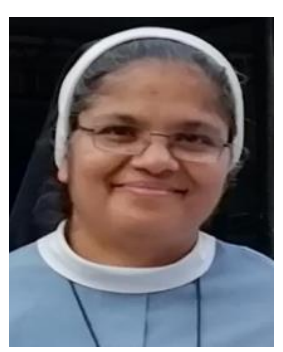

Author Sr. Thresiamma NC. (Sr. Litty SH) is a Research Scholar in Himalayan University, Itanagar in Arunachal Pradesh, India. She has attended various Seminars and conferences.

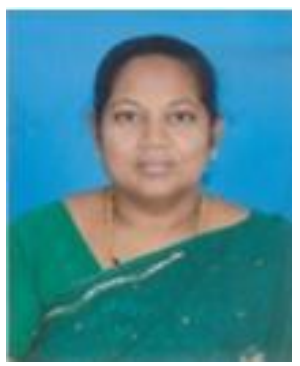

Author Dr. S. Rajina Rani is an active researcher with many publications in her name. She has attended and organised various National and International conferences and has given extensive lectures. At present she is research supervisor, Himalayan University, Itanagar in Arunachal Pradesh, India. 


\section{INTRODUCTION}

Nursing is a science and art which requires a sound type of education and a thorough knowledge of human behaviour. Art is a skill in doing something that is acquired by study and practice. An act is a body of practical knowledge which tells us have to work to produce certain results. Intravenous cannulation is a common invasive procedure for most of the patients in clinical settings. Most of the inpatients, about $90 \%$ receive IV infusion therapy as their part of their treatment. For the good venous access, an expert is needed for the procedure. Initially IV cannulation requires more challenging skills. Nurses are very committed to initiate, monitor and maintain IV infusion in a competent way to ensure the safety and maintain standardized care to the patient (Jaya, 2017).

Intravenous cannulation is one of the common invasive procedures for the patients in clinical and community settings. Millions of patients are receiving treatment medicine via intravenous infusion therapy for life saving and also correcting metabolic disorders through drugs, nutrition, solution and blood products. Administration of medicine is one of the greatest responsibility of a nurse for that they should have enough knowledge regarding how to plan and insert a cannula without developing complications which is the basic nursing education since in 1950's in Sweden (KGeorge,2020). The service offered by a profession are based on specialized knowledge and skills that have been developed in a scientific and learned manner.

Peripheral intravenous device were introduced more than forty years ago. Dr. Thomas Latta was introduced intravenous therapy in 1813, and applied in Cholera pandemic in 1832. Modification was performed by Hirschfild Hyman in 1930. Peripheral standardised IV are simple, low cost and easy to perform for medication and other type of fluids, which can placed in an arm of foot. (Sandeep, 2017). PIVC is the method of an insertion of a flexible plastic devise with a style available, inserted in to the vein for the therapeutic and diagnostic purpose.(A.Hassain,2016).To ensure the safe and competent administration of drug therapies the professional one who is performing the procedure should have knowledge about the anatomical and physiological structure of the vascular system and professionally competent and skilled to perform successfully.

In all health care settings IV infusion is a key procedure in almost all parenteral nutrition groups of medications (Gulcan, 2018). If the nurses are not competent enough in insertion of intravenous cannula there may be chances of developing complications like fungal and bacterial infections, dis-lodgement, leakage, infiltration, extravasation, thrombophlebitis, and vascular wall damage results delay in treatment. So the comfort and safety of the patient, successful insertion of cannula in a first attempt is utmost important. And to eradicate further developing complications they need better knowledge and essential practical skills main concern. (Sachi, 2018). In modern era nurses must have updated knowledge and practical skills in performing PIVC to improve the standardized care which promote quality of life of the patient. Because of these negative impacts from omissions and commissions related to person's inadequate knowledge and practical skills to perform IV cannula in successful way, the investigator felt the need of assessing skills, knowledge and practice on intravenous cannulation is an important concern on their task.

\section{STATEMENT OF THE PROBLEM}

"A study to assess the level of knowledge and practice on an intravenous cannulation among nurses in selected Hospital, Idukki District, Kerala".

\section{OBJECTIVES OF THE STUDY}

- To assess the level of knowledge and practice regarding intravenous cannulation among nurses

- To determine the association between knowledge and practice with selected demographic variables HYPOTHESIS

- There will be a significant differences between in knowledge and practice level of nurses in an intravenous cannulation

- There will be a significant association between knowledge and practice with selected $v$ demographic variables.

\section{REVIEWS OF LITERATURE}

A descriptive cross sectional study was conducted to assess the level knowledge and practice on cannulation and its complication among staff nurses. Self-structured questionnaire and observational checklist were used to collect the data. Total of 16900 articles were retrieved and 96 were selected manually. Most of the finding revealed that nurses had poor knowledge and practice regarding cannulation. (Lalit Sharma, 2019)

Another descriptive cross sectional study was conducted in Nepal to assess the knowledge and practice towards IV cannulation among nurses. $84.72 \%$ had correct practical skills and $82.47 \%$ had good knowledge on IV insertion. Structured questionnaire was used to gather the data and analysed with SPSS 20 version. 200 subjects were selected. (Chadani Osti 2019). 


\section{ARTICLES}

A descriptive study was conducted to assess the knowledge and practice in IV cannulation among nurses in Ismailia City. 81 staff nurses were selected as samples. For data collection structured questionnaire and checklist was used. Data analysed by SPSS Version 20. $50.6 \%$ had adequate knowledge regarding IV cannulation. 92.6\% had poor practical skills on IV procedure. (Wafaa, 2019).

A descriptive study was conducted to assess the knowledge and practice on IVC among nurses in District Hospital Mohali. 60 staffs were recruited by convenient sampling technique and data was gathered with structured questionnaire and observational rating scales were used. Results showed that $61.66 \%$ had average level of knowledge, $37 \%$ had good level and $93.30 \%$ had average practical skills, $0.05 \%$ had poor practical skills.

(Sandeep K, 2017)

\section{RESEARCH METHODOLOGY}

Qualitative approach was used for this study.

Research design: The design was used Descriptive research design.

Setting: Staffs who are working in medical, surgical, and critical department of selected hospital, Idukki.

Sample size: 48staffs registered under INC, who met the inclusion criteria.

Sampling technique: Non probability Convenience sampling techniques were used.

Data collection tool

Part 1: Demographic and Clinical data which includes age, gender, professional qualification, year of experience and participation in CNE programme

Part 2: Self structured questionnaire and Observational Check list.

Structured questionnaire, it consisted of 30 questions regarding the anatomical and physiological aspects of IV cannulation.

Observational checklist consisted of 16 items to evaluate their skill performance on IVC.

Data analysis

Based on the hypotheses data was analysed with inferential and descriptive statistics.

RESULTS:

Table 1: Distribution of the samples based on demographic and clinical variables

\begin{tabular}{|c|c|c|c|c|c|c|c|}
\hline SI.No & Variables & $f$ & $\%$ & SI.No & Variables & $f$ & $\%$ \\
\hline 1 & 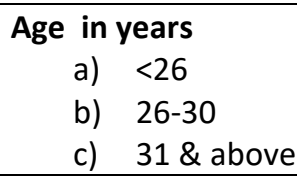 & $\begin{array}{l}12 \\
20 \\
16 \\
\end{array}$ & $\begin{array}{l}25 \\
47.1 \\
33.3 \\
\end{array}$ & 5 & $\begin{array}{l}\text { Area of work } \\
\text { a) Medical } \\
\text { b) Surgical } \\
\text { c) Critical area }\end{array}$ & $\begin{array}{l}18 \\
9 \\
21 \\
\end{array}$ & $\begin{array}{l}37.5 \\
18.8 \\
43.8 \\
\end{array}$ \\
\hline 2 & $\begin{array}{l}\text { Gender } \\
\begin{array}{l}\text { a) Male } \\
\text { b) Female }\end{array}\end{array}$ & $\begin{array}{l}5 \\
43\end{array}$ & $\begin{array}{l}10.4 \\
89.6\end{array}$ & 6 & $\begin{array}{l}\text { Previous experience } \\
\text { area } \\
\text { a) Medical } \\
\text { b) Surgical } \\
\text { c) Critical area }\end{array}$ & $\begin{array}{l}17 \\
9 \\
22\end{array}$ & $\begin{array}{l}35.4 \\
18.8 \\
45.8\end{array}$ \\
\hline 3 & $\begin{array}{l}\text { Education } \\
\begin{aligned} \text { a) } & \mathrm{GNM}(\mathrm{N}) \\
\text { b) } & \mathrm{BSC}(\mathrm{N}) \\
\text { c) } & \mathrm{PBBSC}(\mathrm{N})\end{aligned}\end{array}$ & $\begin{array}{l}26 \\
16 \\
6\end{array}$ & $\begin{array}{l}54.2 \\
33.3 \\
12.5\end{array}$ & 7 & $\begin{array}{l}\text { No of CNE attended } \\
\text { a) Nil } \\
\text { b) } 1-2 \text { times } \\
\text { c) } 3 \& \text { more }\end{array}$ & $\begin{array}{l}0 \\
18 \\
22\end{array}$ & $\begin{array}{l}0 \\
37.5 \\
45.8\end{array}$ \\
\hline 4 & $\begin{array}{l}\text { Year of experience } \\
\text { a) <3yrs } \\
\text { b) } 3-6 y r s \\
\text { c) }>6 \text { yrs. }\end{array}$ & $\begin{array}{l}11 \\
28 \\
9 \\
\end{array}$ & $\begin{array}{l}22.9 \\
58.3 \\
18.3\end{array}$ & & & & \\
\hline
\end{tabular}

Table 2: Mean and SD of knowledge and practice on IVC.

\begin{tabular}{|l|l|l|}
\hline Variables & Mean & SD \\
\hline Knowledge on IVC & 12.54 & 3.585 \\
\hline Practice on IVC & 9.94 & 1.929 \\
\hline
\end{tabular}




\section{ARTIC LES}

Figure 1: Level of staff knowledge and practice on IVC.

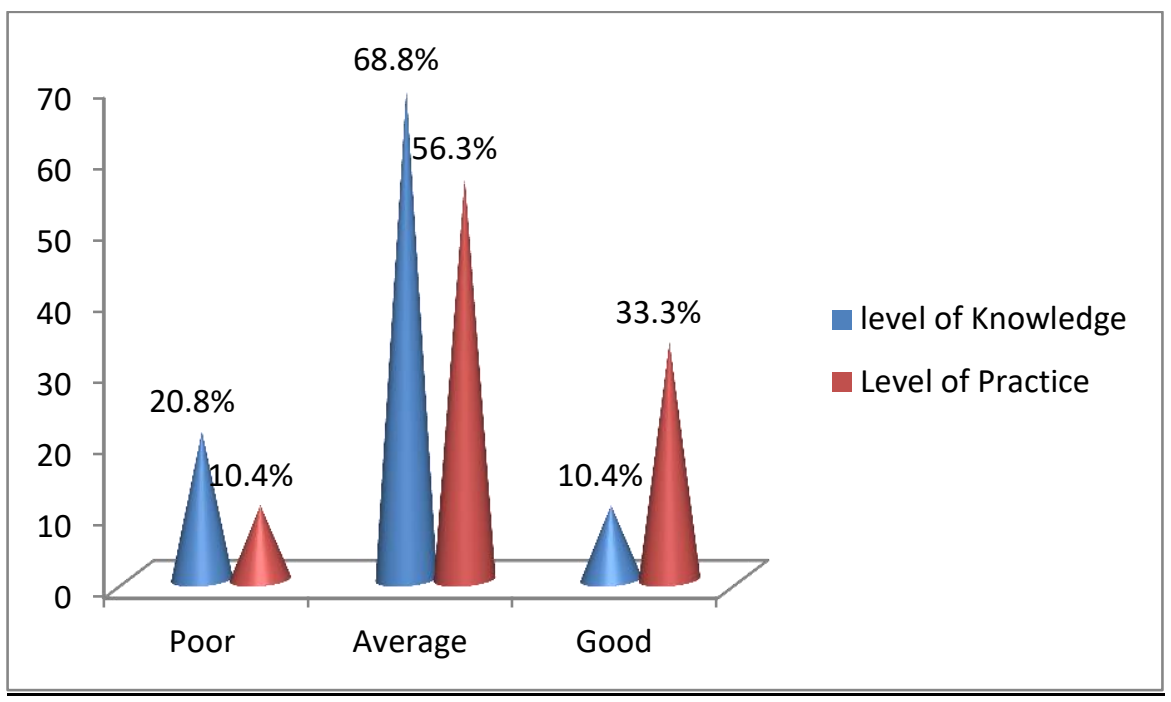

Table 3: Correlation between knowledge and practice scores on Intravenous Cannulation

\begin{tabular}{|ll|l|l|}
\hline Variables & Knowledge & Practice \\
\hline \multirow{2}{*}{ knowledge } & Pearson Correlation & 1 & 0.156 \\
& Sig. (2-tailed) & & 0.290 \\
& N & 48 & 48 \\
practice & Pearson Correlation & 0.156 & 1 \\
& Sig. (2-tailed) & 0.290 & \\
& N & 48 & 48 \\
\hline
\end{tabular}

Table 4: Frequency and percentage of practice among staffs on IVC

\begin{tabular}{|l|l|l|l|l|l|}
\hline SI.No & Observation Check list for IVC & $\mathbf{f}$ & $\%$ & $\mathbf{f}$ & \% \\
\hline & & Right & Wrong & \\
& & Answer & & \\
\hline 01 & Verify doctors order & 8 & 16.7 & 40 & 83.3 \\
\hline 02 & Check for allergies & 2 & 4.2 & 46 & 95.8 \\
\hline 03 & Gather proper equipment & 8 & 16.7 & 40 & 83.3 \\
\hline 04 & Wash hand & 31 & 64.6 & 17 & 35.4 \\
\hline 05 & Identification of the patient & 25 & 52.1 & 23 & 47.9 \\
\hline 06 & Self-introduction and explanation & 33 & 66.8 & 15 & 31.3 \\
\hline 07 & Assessment and selection of vein & 47 & 97.9 & 1 & 2.1 \\
\hline 08 & Prepare all equipment before IVC & 10 & 20.8 & 38 & 79.2 \\
\hline 09 & Apply tourniquet properly & 15 & 31.3 & 33 & 66.8 \\
\hline 10 & Select site for puncture & 46 & 95.8 & 2 & 4.2 \\
\hline 11 & Correct identification \& provision of warmth & 45 & 93.4 & 3 & 6.3 \\
\hline 12 & Cleaning are as per policy & 31 & 64.6 & 17 & 35.4 \\
\hline
\end{tabular}




\begin{tabular}{|l|l|l|l|l|l|}
\hline 13 & Successful performance of IVC & 46 & 95.8 & 2 & 4.2 \\
\hline 14 & Verify placement by aspirating blood & 46 & 95.8 & 2 & 4.2 \\
\hline 15 & Dresses, tapes, and label as per policy & 44 & 91.9 & 4 & 8.3 \\
\hline 16 & Documentation & 41 & 85.4 & 7 & 14.6 \\
\hline
\end{tabular}

\section{DISCUSSION}

Section 1: Distribution of samples based on demographic and clinical data.

The demographic and clinical variables selected for this study were age, gender, professional education, year of experience, area of previous clinical exposure.

Frequency and percentage distribution of demographic an clinical data, most of them belongs to the age group between 26 and 30(41.7\%), and above 37 age group (33.3\%). Similarly study supported that age between 20 to 25(52\%) and 26 to 30 (44\%) were included. (Vipina Saji, 2016). Most of them (59\%) are in age less than 24 in another study. (Wafaa, 2019). Majority of the samples were (89.6\%) female and supported with other findings like $87 \%$ were female (Ahsa T, 2016). Regarding professional qualification half of them (54.2\%) were in general nursing category and $33.3 \%$ were Bachelors of nursing. Supporting evidence were $57 \%$ BSc and $40 \%$ were GNM in another study. (Asha T, 2016). Majority of them qualified as (94\%) GNM in another study. (Anwar Hossain, 2016).

Years of experience in this study show $58.8 \%$ had three to six years of experience. Where as in other findings shows $42 \%$ had less than one year experience in the clinical area.(VipinaSaji, 2016) and half of them(57\%) had less than three years of experience.(Chadani, 2019). In the present study, most of them (43.8\%) are working in Critical are. It is supported by the staff working $30 \%$ were in medical wards and $18 \%$ were in critical area. (Sandeep Kaur, 2018). Based on the exposure of CNE on IVC, this study shows $45.8 \%$ were attended CNE more than three times. In another study estimated that $66 \%$ of the staffs attended CNE on IVC. (Jyothi Kapoor, 2017).

\section{Section 2: Level of knowledge and practice on IVC}

The findings of the present study shows the levels of knowledge were poor in few (20.8\%), majority had average (68.8\%) and minimum are good level of knowledge. (10.4\%) Regarding practical experts, half of them (56.3\%) had average level of practical skills. Whereas $33.3 \%$ had good level of practical skills in IVC. These findings supported by other studies are $49.7 \%$ and $25.5 \%$ had good and average level of knowledge respectively. Also $73.3 \%$ and $14.6 \%$ had average and good level of practical skills in IVC. (A Hossain, 2016). Other findings show that $83 \%$ had average level of knowledge and $90 \%$ had average practice on IVC. (Asha T, 2016). Similarly $93.3 \%$ had good practical skills and $61.66 \%$ had average level of knowledge. (Sandeep Kaur, 2018) and also $82.47 \%$ had good knowledge and84.72\% good practical skills on IVC. (Chadani, 2019). Other findings revealed that there were $65 \%$ samples had good knowledge and $42 \%$ of practical skills on IVC (Lalit Sharma, 2019).

Section 3: Association of level of knowledge and practice with selected variables.

In the present study there were no association of knowledge and practice on cannulation with demographic and clinical data. This study also supported with other study findings which has no association with demographic variables. (Wafaa, Sandeep Kaur and Khairunica, 2019). One study findings showed that there were association of knowledge and practice with clinical experience. (Nungolima, 2018)

Section 4: Correlation between knowledge and practice on IVC among staff nurses.

In this study there is a positive correlation of level of knowledge and practice among staff nurses on IVC. $(r=1)$.Similarly other studies also supporting these findings. SKaur says that there is weak positive correlation between knowledge and practice. (S Kaur, 2017). Other studies shows positive correlation between level of knowledge and practical expertness on IVC, $r=0.36$ at 0.01 level. (Jaya Thaka, 2017).

\section{CONCLUSION}

The present study was done to evaluate the level of knowledge and practice on IVC among staff nurses in selected hospital. The objective of the study was to assess the level of knowledge and practice on IVC and to determine the association with demographic and clinical variables. After meeting the inclusion criteria, 48 samples were selected with non-probability sampling techniques. Self-prepared questionnaire was instituted to acquire the knowledge data and observational check list were applied to evaluate the practical performance of the staff nurses on IVC. Score was recorded in the sample data sheet. Confidentiality was maintained throughout the study. Study was concluded with the findings of the data interpretation. The level of knowledge on IVC among staff nurses were poor(20.8\%), average (68.8\%) and good (10.4\%). Where as practical 
skills on IVC among participants were good(33.3\%), average (56.3\%), and poor performance (10.4\%). There were no association of knowledge and practice on clinical and demographic variables. Findings shows Positive correlation $(r=1)$ between knowledge and practice on IVC. Study concluded that staffs has to improve their knowledge and practical skill to impart quality care to the patient thus maintain the standard of care and enhance the prestige of the institution which they dedicate their work.

\section{LIMITATIONS AND RECOMMENDATIONS}

- Sample size was small, so generalization of study findings is limited.

- Shortage of the staffs and over timing work cause negative impact of the observer

- Study settings can be replicated in different settings

- STP (structured teaching programme), and skill training programmes could be included to furnish their knowledge and skill performance on IV cannulation

\section{REFEERENCES}

1. AshaAniyan T, Sartaaj Perveen. A Study To Assess The Knowledge And Practice Regarding Intravenous Cannulation Among Staff Nurses In Selected Hospital New Delhi., International Journal Of Nursing And Midwifery Research, 2016, 3.

2. G Khairunniza, C Leela and S Thiruselvi "students' perception of their knowledge about peripheral intravenous cannulation at a private medical university in seremban, negeri Sembilan, ADVED 20195th International Conference on Advances in Education and Social Sciences 21-23 October 2019Istanbul, Turkey; ISBN: 978-605-82433-7-8

3. George K, Muninarayanappa B. Effectiveness of structured teaching program on knowledge and practices of staff nurses on prevention of intravenous cannulae complications. Arch Med Health Sci 2013; 1:115-9.

4. GulcanBahceciogluTuran. 'Nursing Students' Levels of Knowledge on the Prevention of Intravascular Catheter Infections, International Journal of Caring Sciences. January-April 2018 Volume 11 | Issue 1| Page 443

5. Hossain AM, Hasan MIA, Haque M. Assessment of the level of knowledge and practice on intravenous cannulization among staff nurses of selected tertiary care hospital in Dhaka city. MOJ Public Health.2016; 4(5): 156-159. DOI: 10.15406/mojph. 2016.04.00095

6. Jyoti Kapoor. A Descriptive Study To Assess The Knowledge And Knowledge On Practice Regarding Peripheral Intravenous Infusion Among GNM (Nursing) 3 rd Year Students At AMT School, Bakshi Nagar ,Jammu, International Journal of Advanced Research And Development. 2017; 2:269 -271.

7. Jaya Thanga Selvi G. A study to assess the knowledge and practice of nursing personnel regarding intravenous therapy and its selected complications, International Journal of Nursing and Healthcare Research, 1(1), 2017, 19 - 22.

8. Lalit Shree Sharma, Ishak Mohammad; The knowledge and practice regarding intravenous cannulation and its complications: A narrative review, International Journal of Advanced Scientific Research ISN: 2456-0421; Volume 4; (4); July 2019; Page No. 78-81

9. N. Nungoleima $C$ et al. Study to Assess the Effectiveness of Structured Teaching Program on Knowledge Regarding Intravenous Cannulation for Under Five Children Among Staff Nurses. jolnt J Nur Today 2018 Vol. 8 (1). www.jolnt.com 22.[e ISSN 2456-1630]

10. Pankaj Punjot, Jincy Mathew, Saly Suseel, Valsa Thomas, A study to assess the effectiveness of infusion experts on the nursing interventions of peripheral intravascular devices among patients admitted to a tertiary care hospital of the city. International Journal of Nursing Research (IJNR) IJNR, Vol 4 (3), 171-175, 2018

11. Sachi J. Christian and Dr. Anil Sharma, A literature review to identify pain relieving interventions and effect during intravenous cannulation. International journal of advanced research. DOI URL: http://dx.doi.org/10.21474/IJAR01/6900.

12. VipinaSaji. An Exploratory Study To Assess The Knowledge Regarding Peripheral Intravenous Cannulation Among Nursing Staff In A Selected Hospital Of Indore City, International Journal Of Advanced Research (IJAR). 2016; 4(9):2073-2076. 